\title{
Circadian variations in central corneal thickness and intraocular pressure in patients with glaucoma
}

\author{
P Fogagnolo, L Rossetti, F Mazzolani, N Orzalesi
}

Br J Ophthalmol 2006;90:24-28. doi: 10.1136/bjo.2005.079285

Aim: To analyse 24 hour variations in intraocular pressure (IOP) and central corneal thickness (CCT) in a group of glaucomatous patients.

Methods: 30 patients with primary open angle glaucoma were hospitalised and underwent circadian evaluations (at $8 \mathrm{pm}$, midnight, $4 \mathrm{am}, 8 \mathrm{am}$, noon, and $4 \mathrm{pm}$ ) of supine and sitting IOP, respectively, measured using a Perkins and a Goldmann tonometer, and CCT measured using an ultrasonic pachymeter (the mean value of three measurements within $5 \mu \mathrm{m}$ ). All patients were treated with timolol $0.5 \%$ twice daily and latanoprost $0.005 \%$ once daily.

Results: Mean supine IOP was 15.3 (SD 3.7) $\mathrm{mm} \mathrm{Hg}$ (range 10-25), with circadian fluctuations of $7.3(3.3) \mathrm{mm} \mathrm{Hg}$. Mean sitting IOP was 15.1 (3.9) $\mathrm{mm} \mathrm{Hg}$ (range 8-26), with circadian fluctuations of $5.4(3.1) \mathrm{mm} \mathrm{Hg}$. Mean CCT was 534 (39) $\mu \mathrm{m}$ (range $443-637 \mu \mathrm{m}$ ) with circadian fluctuations of $16.5(6.2) \mu \mathrm{m}$ (range 6-31 $\mu \mathrm{m}$ ). Both the within patient and within time point fluctuations in CCT were statistically significant $(p<0.0001$, ANOVA).

Conclusions: The authors found considerable fluctuations in 24 hour IOP. The circadian fluctuations in CCT were small and, although statistically significant, did not seem to interfere with the circadian IOP assessment.

I ntraocular pressure (IOP) is an important parameter for glaucoma detection and follow up and, since the beginning of its medical treatment, reducing IOP has been the only way of slowing or halting disease progression. Like all biological parameters, IOP fluctuates over 24 hours, ${ }^{1-5}$ but the extent of the fluctuations and their importance in glaucoma patients are still debated..$^{6-9}$

The "gold standard" for IOP evaluation is Goldmann tonometry, which is highly precise and shows the least interobserver variability. However, various factors can reduce its reliability, ${ }^{10-14}$ one of the most important of which is central corneal thickness (CCT). Although the effect of CCT on IOP measurements was assumed by Goldmann ${ }^{12}$ in 1957, and then experimentally demonstrated by Ehlers ${ }^{15}$ in 1975, it is only recently that the problems in measuring IOP created by refractive surgery have underlined its clinical importance. ${ }^{16}{ }^{17}$ Though a number of cross sectional studies have shown that ocular hypertensive eyes have thicker mean $\mathrm{CCT}^{18-23}$ whereas low tension glaucoma (LTG) is characterised by lower mean CCT, ${ }^{12}{ }^{23-25}$ and primary open angle glaucoma (POAG) by normal mean CCT, ${ }^{19} 21$ individual corneal thickness largely varies and overlaps between groups. Nevertheless, pachymetry is important to correctly classify and diagnose these conditions. ${ }^{1819212326}$

There are still many unanswered questions concerning CCT. First of all, although many correcting factors have been proposed in order to obtain an estimate of "actual" IOP with respect to CCT, there is still no agreement about their clinical usefulness. ${ }^{15} 222327-29$

Furthermore, there is no pachymetric "gold standard." Ultrasonic pachymeters are the most used in clinical settings; they are generally portable and easy to use, but they require adequate training because probe alignment and perpendicular contact with the central cornea are critical to ensure reliable data. $^{30}$ Ultrasonic pachymetry provides the most precise CCT measurements, ${ }^{30}$ and its interoperator and intraoperator reproducibility is good, ${ }^{31}$ but its accuracy has recently been questioned because it can overestimate CCT in comparison with confocal microscopy. ${ }^{30}$ In an attempt to avoid these limitations, various non-contact pachymeters (optical devices, confocal microscopy, ${ }^{32}$ and optical coherence tomography ${ }^{33}$ ) have been introduced into clinical practice.

The variability of corneal thickness is a further controversial issue. Most studies have considered CCT a "static" parameter and ignored its possible fluctuations (as correctly pointed out in Doughty's meta-analysis ${ }^{34}$ ), and more recent studies of CCT variability have considered only daytime fluctuations, ${ }^{31}{ }^{35}$ with the exception of Harper's study of circadian variations in normal subjects. ${ }^{36}$

The aim of this study was to evaluate the circadian fluctuations of CCT in a group of glaucomatous patients, and their potential effects on IOP assessments.

\section{PATIENTS AND METHODS}

The study was carried out at the San Paolo Hospital Eye Clinic of the University of Milan. The patients attending the glaucoma service underwent a complete ophthalmic examination in order assess their eligibility, and 30 consecutive glaucomatous patients were enrolled (see table 1). In order to avoid the effects of different medical treatments, only patients treated with an unfixed association of timolol maleate $0.5 \%$ twice daily and latanoprost $0.005 \%$ once daily were considered.

The inclusion criterion was bilateral POAG, defined as an untreated IOP $>21 \mathrm{~mm} \mathrm{Hg}$ (measured on two consecutive occasions separated by an interval of at least 2 hours but no more than 12 weeks), a glaucomatous visual field (on the basis of at least two reliable Humphrey 30-2 full threshold tests), and glaucomatous optic disc changes (evaluated by means of colour stereophotographs) or retinal nerve fibre layer defects (evaluated by means of a scanning laser ophthalmoscope).

The exclusion criteria were low tension, exfoliation, pigmentary or secondary glaucomas; previous refractive surgery; any ocular surgery less than 3 months before enrolment; present or past contact lens wear; present or past corneal disease or injury; significant tear secretion

Abbreviations: CCT, central corneal thickness; COV, coefficient of variation; CPSD, corrected pattern standard deviation; IOP, intraocular pressure; LTG, low tension glaucoma; MD, mean defect; POAG, primary open angle glaucoma 


\begin{tabular}{|ll|}
\hline Table 1 & Main patient \\
\hline Number of subjects & 30 \\
Race, white & 30 \\
Age range, years & $55-84$ \\
Sex & $12 \mathrm{~F}, 18 \mathrm{M}$ \\
Refraction (D), mean (SD) & $-0.9(4.2)$ \\
MD (dB), mean (SD) & $-6.6(8.0)$ \\
CPSD (dB), mean (SD) & $5.6(4.5)$ \\
\hline MD: mean defect; CPSD: corrected pattern standard \\
deviation. \\
\hline
\end{tabular}

abnormality; significant wake-sleep rhythm disturbances; and hypnotic drug consumption.

Before enrolment, the procedures and the aims of the study were carefully explained to the patients, who signed an informed consent form approved by the ethics committee of San Paolo Hospital. The study was performed according to the Declaration of Helsinki.

The enrolled patients were hospitalised at $7 \mathrm{pm}$ to undergo a circadian evaluation of CCT, and supine and sitting IOP in one randomly chosen eye (randomisation by means of a list of random numbers), as previously described. ${ }^{45}$ Briefly, the measurements were made at $8 \mathrm{pm}$, midnight, $4 \mathrm{am}, 8 \mathrm{am}$, noon, and $4 \mathrm{pm}$; the $8 \mathrm{pm}$, and 8 am measurements were made before the instillation of timolol maleate $0.5 \%$. Latanoprost was instilled at $10 \mathrm{pm}$.

One drop of oxibuprocaine and fluorescein was instilled before each measurement. Supine IOP was measured by means of a Perkins tonometer, after which the patients walked about 10 metres to the ophthalmic cabinet and their sitting IOP was measured using a Goldmann tonometer. Finally, CCT was measured on the mid-pupillary/papillary axis (the mean of three readings within $5 \mu \mathrm{m}$ ) using a DGH 2000 AP ultrasonic pachymeter (DGH Technology Inc, San Diego, CA, USA).

A slit lamp examination was performed before each CCT measurement in order to ensure the absence of corneal epithelial defects. No dilation or gonioscopy was used during the study period in order to avoid any corneal surface damage or distortion. ${ }^{37}$

\section{Statistical analysis}

The tonometric measurements were made by two experienced observers (PF and FM), whose concordance was evaluated before the eligibility examination by means of the calculation of kappa statistics $(\kappa)^{38}$ over 50 measurements each using the Perkins and Goldmann tonometers. A cut-off point of $2 \mathrm{mmHg}$ (the lowest published interobserver variability for Goldmann tonometry) ${ }^{39}$ was used to define agreement, which was found to be excellent $(\kappa=0.84)$.

The CCT measurements were made by a single observer (PF). Intraobserver agreement was evaluated by comparing 50 CCT measurements of a single eye of a volunteer. Ten measurements were made on the same day at each time point of $8 \mathrm{am}, 10 \mathrm{am}$, noon, $2 \mathrm{pm}$, and $4 \mathrm{pm}$, and agreement was defined as the presence of values within plus or minus $5 \mu \mathrm{m}$ of the mean CCT (corresponding to the 95\% confidence interval $^{40}$ ). The mean CCT was 507 (SD 3) $\mu \mathrm{m}$, and the agreement was excellent $(\kappa=0.94)$.

The IOP and CCT data are given as mean values, standard deviations, and ranges. The coefficient of variation (COV, defined as the percentage standard deviation divided by the mean) was also calculated in order to facilitate comparisons with the variations reported in other studies.

The $t$ test for paired samples was used to compare mean supine and sitting IOP. Two way analysis of variance for repeated observations ${ }^{38}$ was used to test the hypothesis that there were no significant within patient or within time point changes in CCT changes during the circadian evaluation.

The Bravais-Pearson coefficient of linear correlation $(\rho)$ was used to check the correlations between the following variables: mean CCT; variations in CCT (percentage, standard deviation, and COV); mean supine IOP; variations in mean supine IOP; mean sitting IOP; variations in mean sitting IOP; mean defect and corrected pattern standard deviation at standard automated perimetry; and refraction. The correlation was considered negligible if $\rho<0.2$; weak if $0.2<\rho<0.5$; good if $0.5<\rho<0.8$; strong if $\rho>0.8$. $^{38}$

\section{RESULTS}

The key results of the study are summarised in table 2. IOP and CCT data of patients operated of cataract surgery (seven patients) or trabeculectomy (two patients) were comparable to data of patients who did not undergo eye surgery.

Mean supine IOP was 15.3 (SD 3.7, range 10-25) $\mathrm{mm} \mathrm{Hg}$; mean sitting IOP was 15.1 (SD 3.9, range 8-26) mm Hg; and mean CCT was 534 (SD 39, range 443-637) $\mu \mathrm{m}$ (see fig 1 for the distribution of mean CCT values).

Table 2 Main results of the study

\begin{tabular}{|c|c|c|c|}
\hline & $\begin{array}{l}\text { Supine IOP } \\
(\mathrm{mm} \mathrm{Hg})\end{array}$ & $\begin{array}{l}\text { Sitting IOP } \\
(\mathrm{mm} \mathrm{Hg})\end{array}$ & $\mathrm{CCT}(\mu \mathrm{m})$ \\
\hline Mean value & 15.3 & 15.1 & 534 \\
\hline Standard deviation & 3.7 & 3.9 & 39 \\
\hline Range & $10-25$ & $8-26$ & $443-637$ \\
\hline Coefficient of variation & $24.2 \%$ & $25.8 \%$ & $7.3 \%$ \\
\hline \multicolumn{4}{|c|}{ Mean results at each time point } \\
\hline $8 \mathrm{pm}$ & 15.2 & 15.3 & 529.8 \\
\hline Midnight & 16.5 & 15.7 & 535.9 \\
\hline $4 \mathrm{am}$ & 15.7 & 15.0 & 538.9 \\
\hline $8 \mathrm{am}$ & 15.9 & 15.2 & 535.5 \\
\hline Noon & 14.2 & 14.9 & 531.7 \\
\hline $4 \mathrm{pm}$ & 14.2 & 14.8 & 529.5 \\
\hline Standard deviation* & 0.93 & 0.34 & 3.8 \\
\hline Coefficient of variation* & $6.1 \%$ & $2.6 \%$ & $0.7 \%$ \\
\hline \multicolumn{4}{|c|}{ Mean results per patient over the 24 hours } \\
\hline Coefficient of variation (SD & $18.8 \%(7.5 \%)$ & $13.4 \%(6.7 \%)$ & $1.2 \%(0.4 \%)$ \\
\hline Range & $6.6 \%-33.1 \%$ & $3.6 \%-36.5 \%$ & $0.4 \%-2.4 \%$ \\
\hline Mean individual variation & $7.3(3.3)$ & $5.4(3.1)$ & $16.5(6.2)$ \\
\hline Percentage (SD) & $63 \%(33 \%)$ & $45 \%(33 \%)$ & $3.2 \%(1.2 \%)$ \\
\hline Range & $3-15$ & $1-17$ & $6-31$ \\
\hline Percentage & $22 \%-150 \%$ & $7 \%-189 \%$ & $1.1 \%-6.2 \%$ \\
\hline
\end{tabular}




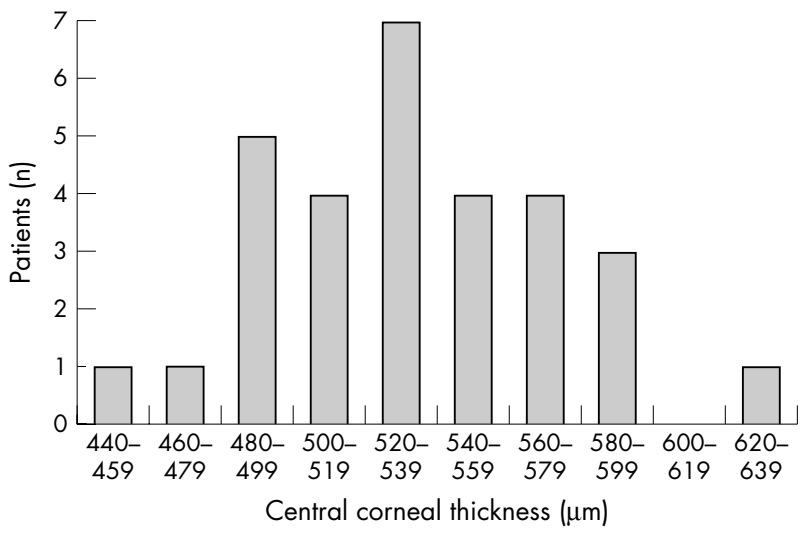

Figure 1 Central corneal thickness in the study population.

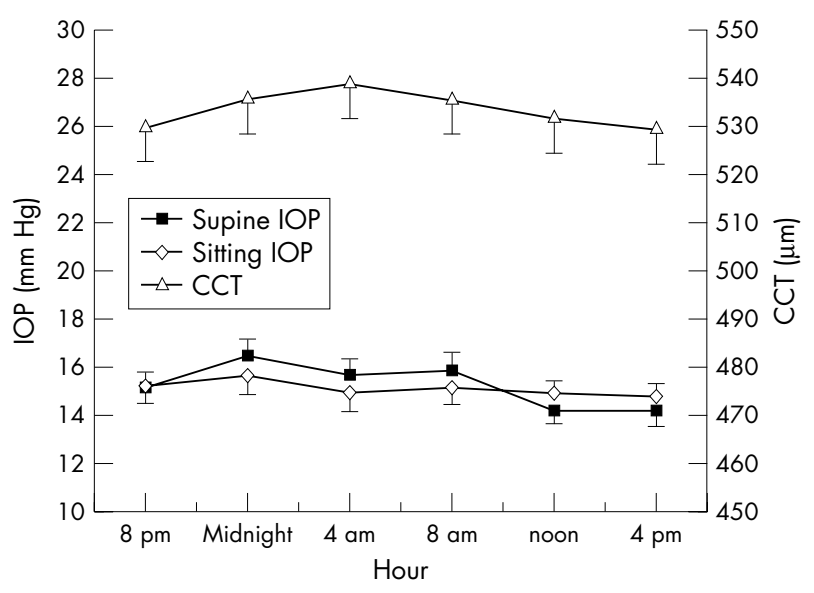

Figure 2 Mean circadian curves of supine IOP $(\mathrm{mm} \mathrm{Hg})$, sitting IOP $(\mathrm{mm} \mathrm{Hg})$, and CCT $(\mu \mathrm{m})$. The bars represent standard errors.

Figure 2 shows the 24 hour curves of mean supine and sitting IOP, and CCT. There were no significant changes in supine IOP at any time point, although it peaked at midnight $(16.5 \mathrm{~mm} \mathrm{Hg})$ and troughed at noon and $4 \mathrm{pm}$ (14.2 $\mathrm{mm} \mathrm{Hg})$, nor any significant change in sitting IOP (mean values between $14.8 \mathrm{~mm} \mathrm{Hg}$ and $15.7 \mathrm{~mm} \mathrm{Hg}$ ). The same was true when the day and night-time measurements were compared. Mean time point CCT ranged from 530$539 \mu \mathrm{m}$, with a $0.7 \%$ COV comparing all time points.

Variability became more important when the within patient curves were considered. The mean variations in

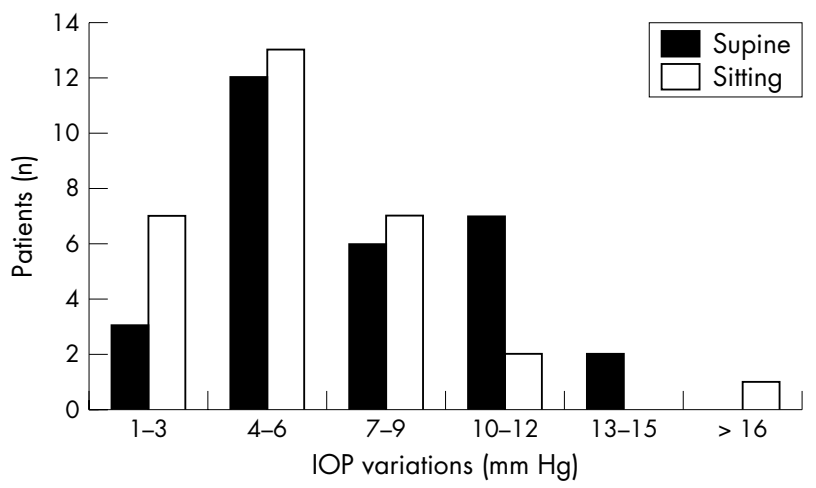

Figure 3 Variations in supine and sitting IOP over 24 hours.

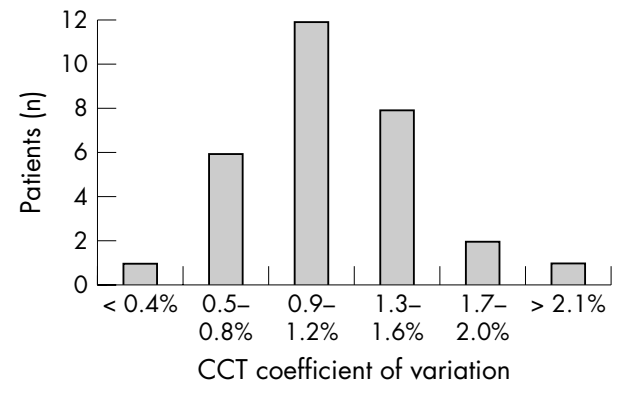

Figure 4 Coefficient of variation (COV) of central corneal thickness (CCT) over 24 hours.

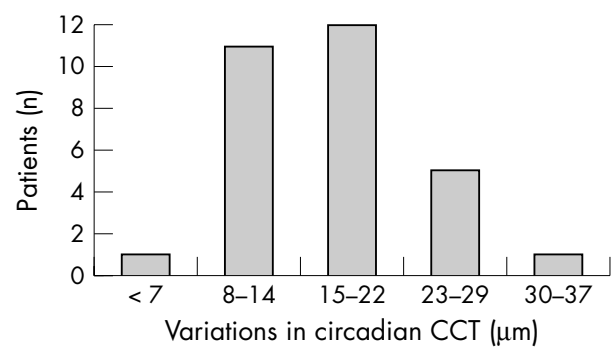

Figure 5 Patient CCT variations $(\mu \mathrm{m})$ over 24 hours.

supine and sitting IOP were respectively 7.3 (3.3) $\mathrm{mm} \mathrm{Hg}$ and 5.4 (3.1) $\mathrm{mm} \mathrm{Hg}$ (fig 3), and mean CCT changes were 16.5 (6.2) $\mu \mathrm{m}$, with mean COV $=1.2(0.4 \%)$ (figs 4 and 5). The distribution of CCT peaks and troughs over time is shown in figure 6. In terms of the values at each time point, the difference between peak CCT (at $4 \mathrm{am}$ ) and trough CCT (at $4 \mathrm{pm})$ was about $9 \mu \mathrm{m}(\mathrm{p}<0.0001$, ANOVA; table 3$)$.

The Bravais-Pearson coefficient of linear correlation was negligible or weak for all of the variables except for the good correlations between mean supine IOP and mean CCT $(\rho=0.53)$, and between mean sitting IOP and mean defect at standard automated perimetry $(\rho=0.64)$. In particular, there were negligible or weak correlations for CCT COV and CCT $(\rho=-0.11)$, mean supine IOP $(\rho=0.02)$ and its variation $(\rho=0.11)$, and mean sitting IOP $(\rho=-0.10)$ and its variation $(\rho=0.42)$.

The CCT curve shown in figure 2 was recalculated in terms of the percentage deviation from the mean (considered as

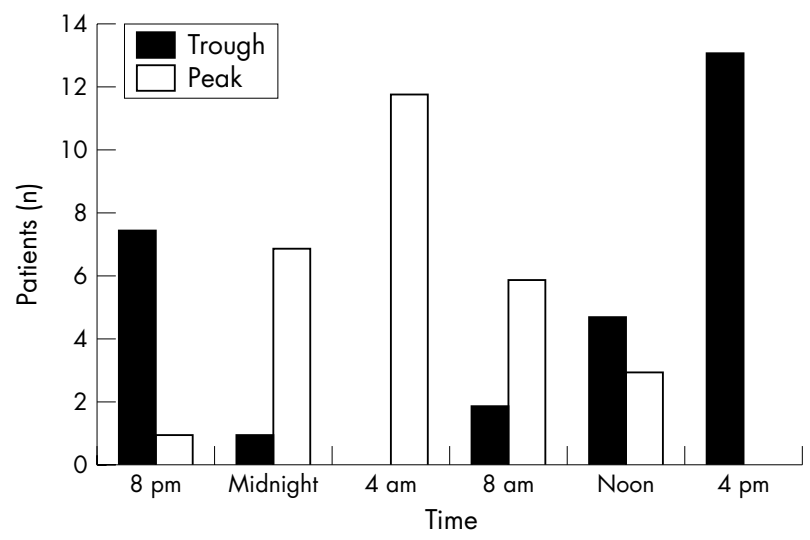

Figure 6 Frequency of CCT peaks and troughs at each time point. Both distribution curves are gaussian, with mean peaks at 4 am and mean troughs at $4 \mathrm{pm}$. 


\begin{tabular}{|c|c|c|c|c|c|}
\hline Source of variation & $\begin{array}{l}\text { Degrees of } \\
\text { freedom }\end{array}$ & Sums of squares & Mean square & $F$ test & $p$ Value \\
\hline Patients & 29 & 267912,561 & 9238,364 & 300 & $<0.0001$ \\
\hline Time points & 5 & 2156,361 & 431,272 & 14 & $<0.0001$ \\
\hline Residual & 145 & 4465,806 & 30,799 & & \\
\hline Total & 179 & 274534,728 & & & \\
\hline
\end{tabular}

$100 \%$ ) in order to compare it with the circadian CCT curve estimated by Doughty in his meta-analysis of normal, nonwhite subjects. ${ }^{34}$ As shown in figure 7 , the two curves were very similar except for the fact that our 24 hour variations did not exceed plus or minus 1\%, whereas Doughty's were about plus or minus $2 \%$.

\section{DISCUSSION}

To the best of our knowledge this is the first study of circadian variations in CCT and their relations to supine and sitting IOP in a group of glaucomatous subjects. A 48 hour study of CCT was published by Harper et al on a small group $(n=8)$ of normal subjects to evaluate fluctuations in CCT during the sleep phase. ${ }^{36}$ Conversely, the main objective of the present study was to evaluate circadian CCT variations in a group of glaucomatous patients and their role in the circadian assessment of IOP.

We found very small variations in circadian supine and sitting IOP, with mean values of respectively 15.3 (0.9) $\mathrm{mm} \mathrm{Hg}$ and 15.1 (0.3) $\mathrm{mmHg}$; the biggest difference of $2.3 \mathrm{~mm} \mathrm{Hg}$ found in the supine curve between midnight and noon values was neither clinically nor statistically significant. When comparing this finding with previously published data, ${ }^{1-5}$ it is necessary to consider the possibility of the treatment induced stabilisation of circadian IOP values.

Greater fluctuations in 24 hour IOP were found when the within patient curves were analysed, with mean variations of 7.3 (range 3-15) $\mathrm{mm} \mathrm{Hg}$ in supine IOP, and mean variations of 5.4 (range 1-17) $\mathrm{mm} \mathrm{Hg}$ in sitting IOP. Goldmann tonometry revealed fluctuations of more than $5 \mathrm{~mm} \mathrm{Hg}$ in about $60 \%$ (fig 3 ) despite the use of treatment schedules that are considered to be very effective in the majority of clinical settings. Although there were no significant differences in daytime $v$ night-time IOP values, $50 \%$ of the supine and $40 \%$ of the sitting IOP peaks occurred at midnight or 4 am, thus

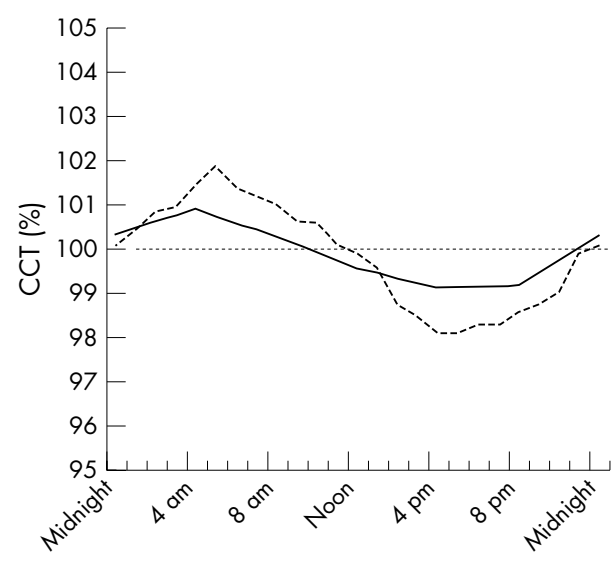

Figure 7 Percentage CCT fluctuations over 24 hours in this study (solid line, plus or minus 1\%) and Doughty's meta-analysis (broken line, plus or minus $2 \%$ ). Both curves intersect the $100 \%$ line at about $10 \mathrm{am} /$ noon; this is reasonably the best interval in which to measure CCT as it is nearest to its mean value. confirming the clinical importance of circadian IOP evaluations in order to be sure of treatment efficacy in glaucomatous patients. ${ }^{45}$ The timings found in our study seem to confirm previous findings by Liu et al in glaucomatous patients ${ }^{40}$ and young healthy subjects. ${ }^{41}$

The mean CCT values were very similar to those reported in the literature. ${ }^{23}{ }^{34}$ The high range in CCT values $(443-637 \mu \mathrm{m})$ in our homogeneous sample of POAG patients receiving the same therapy confirms the importance of individual assessments in better estimating "true" IOP and detecting possible risk factors for disease progression. ${ }^{42}$

The 24 hour variations in CCT were small: mean within patient variation $16.5(6.2) \mu \mathrm{m}(3.2 \mu \mathrm{m}(1.2 \%)$; range 6$31 \mu \mathrm{m}$ ) and mean COV $1.2(0.4 \%)$ (range $0.4-2.4 \%)$. In relation to the mean CCT at each time point, the difference between peak CCT (at $4 \mathrm{am}$ ) and trough CCT (at $4 \mathrm{pm}$ ) was about $9 \mu \mathrm{m}(\mathrm{p}<0.0001)$. This may reflect the well documented changes in corneal metabolism occurring during the night, with increased lactate and corneal swelling. ${ }^{43}$

The circadian CCT curve in the present study was very similar to that of Doughty's meta-analysis of normal, nonwhite subjects, ${ }^{34}$ except for the fact that our fluctuations were smaller (plus or minus $1 \% v$ plus or minus $2 \%$ ). This may have been because of the high degree of intraobserver reproducibility in our study, or to the absence of some factors that may increase CCT variability, such as pregnancy, ${ }^{44}$ menstruation, ${ }^{45}$ or oral contraceptive use.$^{46}$ As shown in figure 7, both curves intersected the $100 \%$ line between 10 am and noon, which is probably the best time to measure CCT as it is nearest to its mean value.

There was a good correlation between mean supine IOP and mean CCT $(\rho=0.53)$, which confirms that an increase in CCT is associated with an increase in IOP. The fluctuations in CCT did not correlate with the other clinical parameters of mean CCT, mean IOP, IOP fluctuations, or refraction.

Harper $^{36}$ found that CCT varied by $7.2 \%$ over 48 hours (with an interval of about 6 hours during the night), as against the $3.2 \%$ observed in our study in which the measurements were continued every 4 hours even during the night. One possible reason for decreased variability in the present study is that disturbances in normal sleep-wake rhythms may change corneal metabolism during the night.

CCT measurements can be theoretically affected when made by means of an ultrasonic pachymeter after applanation tonometry, but two previous studies ${ }^{21} 37$ found no significant influence, and Damji ${ }^{37}$ strongly recommended measuring IOP before CCT. Only one study ${ }^{35}$ has measured CCT before tonometry.

Although avoided in other studies on the grounds that the use of a local anaesthetic may disrupt the epithelial barrier, we followed the usual clinical practice of instilling one drop of oxybuprocaine before our IOP and CCT measurements in order to allow more reliable measurements of both; however, biomicroscopy was regularly used to exclude any changes in the corneal surface at each time point.

It would have been ideally preferable to obtain data from untreated patients because CCT and its variability may be influenced by glaucoma treatment. It has been found that 
timolol may increase $\mathrm{CCT}^{47}$ and latanoprost may decrease it, ${ }^{48}$ but the differences from baseline were small (within plus or minus $1 \%$ ) and can be considered clinically negligible. We therefore preferred to study a homogeneous sample of POAG patients identically treated with the unfixed combination of timolol and latanoprost. No data have been published concerning the effect of glaucoma treatment on circadian fluctuations in CCT.

In conclusion, our data relating to glaucomatous patients suggest that, although statistically significant, circadian CCT fluctuations do not significantly influence circadian IOP measurements, which are crucial when considering glaucoma therapy. With respect to the assumption of Doughty's metaanalysis that "for eyes with chronic disease, [...] even modest changes (that is, 10\%) in CCT can be expected to have a measurable impact on tonometry measures, ${ }^{\prime 34}$ we found fluctuations of only $3 \%$.

\section{Authors' affiliations \\ P Fogagnolo, L Rossetti, F Mazzolani, N Orzalesi, Eye Clinic,}

Department of Medicine, Surgery, and Odontoiatry, San Paolo Hospital, University of Milan, Milan, Italy

Ethics approval: \#985/2003.

Correspondence to: Nicola Orzalesi, Clinica Oculistica, Ospedale San Paolo, Via di Rudinì, 8, 20142 Milan, Italy; fogagnolopaolo@libero.it

Accepted for publication 9 September 2005

\section{REFERENCES}

1 Konstas AG, Katsimbris JM, Lallos N, et al. Latanoprost $0.005 \%$ versus bimatoprost $0.03 \%$ in primary open-angle glaucoma patients. Ophthalmology 2005; 112:262-6

2 Konstas AG, Karabatsas CH, Lallos N, et al. 24-Hour intraocular pressures with brimonidine purite versus dorzolamide added to latanoprost in primary open-angle glaucoma subjects. Ophthalmology 2005;1 12:603-8.

3 Liu JH, Kripke DF, Weinreb RN. Comparison of the nocturnal effects of oncedaily timolol and latanoprost on intraocular pressure. Am J Ophthalmol 2004:138:389-95.

4 Orzalesi N, Rossetti L, Invernizzi T, et al. Effect of timolol, latanoprost, and dorzolamide on circadian IOP in glaucoma or ocular hypertension. Invest Ophthalmol Vis Sci 2000;41:2566-73.

5 Orzalesi N, Rossetti L, Bottoli A, et al. The effect of latanoprost, brimonidine, and a fixed combination of timolol and dorzolamide on circadian intraocular pressure in patients with glaucoma or ocular hypertension. Arch Ophthalmol 2003;121:453-7.

6 Asrani S, Zeimer R, Wilensky J, et al. Large diurnal fluctuations in intraocular pressure are an independent risk factor in patients with glaucoma. J Glaucoma 2000;9:134-42.

7 Bengtsson B, Heijl A. Diurnal IOP fluctuation: not an independent risk factor for glaucomatous visual field loss in high-risk ocular hypertension. Graefes Arch Clin Exp Ophthalmol 2005;243:513-8.

8 Mosaed S, Liu JH, Weinreb RN. Correlation between office and peak nocturnal intraocular pressures in healthy subjects and glaucoma patients. Am J Ophthalmol 2005;139:320-4

9 Nouri-Mahdavi K, Hoffman D, Coleman AL, et al. Advanced Glaucoma Intervention Study. Predictive factors for glaucomatous visual field progression in the Advanced Glaucoma Intervention Study. Ophthalmology 2004;111:1627-35.

10 Azuara-Blanco A, Bhojani TK, Sarhan AR, et al. Tono-Pen determination of IOP in patients with band keratopathy or glued cornea. $\mathrm{Br} J$ Ophthalmol 1998;82:634-6.

11 Drance SM. The coefficient of scleral rigidity in normal and glaucomatous eyes. Arch Ophthalmol 1960;63:668-74.

12 Goldmann H, Schmidt T. Uber applanationstonometrie. Ophthalmologica 1957;134:221-42.

13 Holladay JT, Allison ME, Prager TC. Goldmann applanation tonometry in patients with regular corneal astigmatism. Am J Ophthalmol 1983;96:90-3.

14 Kaufman HE. Pressure measurement: which tonometer. Invest Ophthalmol Vis Sci 1972;11:80-5.

15 Ehlers N, Bramsen T, Sperling S. Applanation tonometry and central corneal thickness. Acta Ophthalmol 1975;53:34-43.
16 Mardelli PG, Piebenga LW, Whitacre MM, et al. The effect of excimer lase photorefractive keratectomy on intraocular pressure measurements using Goldmann applanation tonometer. Surv Ophthalmol 1997;104:945-9.

17 Rashad KM, Bahnassy AA. Changes in intraocular pressure after laser in situ keratomileusis. J Refract Surg 2001;17:420-7.

18 Argus WA. Ocular hypertension and central corneal thickness. Ophthalmology 1995;102:1810-12.

19 Copt RP, Thomas R, Mermoud A. Corneal thickness in ocular hypertension, primary open-angle glaucoma, and normal tension glaucoma. Arch Opthalmol 1999;117:104-5.

20 Herman DC, Hodge DO, Bourne WM. Increased corneal thickness in patients with ocular hypertension. Arch Ophthalmol 2001;1 19:334-6.

21 Herndon LW, Choudhri SA, Cox T, et al. Central corneal thickness in normal, glaucomatous, and ocular hypertensive eyes. Arch Ophthalmol 1997; 115:1137-41.

22 Johnson M, Kass MA, Moses RA, et al. Increased corneal thickness simulating elevated intraocular pressure. Arch Ophthalmol 1977;96:664-5

23 Shah S, Chatteriee A, Mathai M, et al. Relationship between corneal thickness and measured intraocular pressure in a general ophthalmology clinic. Ophthalmology 1999;106:2154-60.

24 Ehlers N, Hansen FK. Central corneal thickness in low-tension glaucoma. Acta Ophthalmol (Copenh) 1974;52:740-6.

25 Morad Y, Sharon E, Hefetz L, et al. Corneal thickness and curvature in normaltension glaucoma. Am J Ophthalmol 1998;125:164-8.

26 Tanaka GH. Corneal pachymetry: a prerequisite for applanation tonometry? Arch Ophthalmol 1998;1 16:544-5

27 Bron AM, Creuzot-Garcher C, Goudeau-Boutillon S, et al. Falsely elevated intraocular pressure due to increased central corneal thickness. Graefes Arch Clin Exp Ophthalmol 1999;237:220-4.

28 Doughty MJ, Zamzn ML. Human corneal thickness and its impact on intraocular pressure measures. A review and meta-analysis approach. Surv Ophthalmol 2000;44:367-408.

29 Whitacre MM, Stein RA, Hassanein K. The effect of corneal thickness on applanation tonometry. Am J Ophthalmol 1993;115:592-6.

30 McLaren JW, Nau CB, Erie JC, et al. Corneal thickness measurement by confocal microscopy, ultrasound, and scanning slit methods. Am J Ophthalmol 2004:137:1011-20.

31 Miglior S, Albe E, Guareschi M, et al. Intraobserver and interobserver reproducibility in the evaluation of ultrasonic pachymetry measurements of central corneal thickness. Br J Ophthalmol 2004;88:174-7.

32 Li HG, Petroll WM, Moller-Pedersen T, et al. Epithelial and corneal thickness measurements by in vivo confocal microscopy through focusing (CMTF). Curr Eye Res 1997;16:214-21.

33 Feng Y, Varikooty J, Simpson TL. Diurnal variation of corneal and corneal epithelial thickness measured using optical coherence tomography. Cornea $2001 ; 20: 480-3$.

34 Doughty MJ, Zaman ML. Human corneal thickness and its impact on intraocular pressure measures. A review and meta-analysis approach. Surv Ophthalmol 2000;44:367-408

35 Shah S, Spedding C, Bhojwani R, et al. Assessment of the diurnal variation in central corneal thickness and intraocular pressure for patients with suspected glaucoma. Ophthalmology 2000;107:1191-3

36 Harper $\mathrm{CL}$, Boulton $\mathrm{ME}$, Bennett $\mathrm{D}$, et al. Diurnal variations in human corneal thickness. Br J Ophthalmol 1996:80:1068-72.

37 Damii KF, Muni RH, Munger RM. Influence of corneal variables on accuracy of intraocular pressure measurement. J Glaucoma 2003;12:69-80.

38 Altman DG. Practical statistics for medical research. London: Chapman and Hall, 1991.

39 Sudesh S, Moseley MJ, Thompson JR. Accuracy of Goldmann tonometry in clinical practice. Acta Ophthalmol (Copenh) 1993;71:185-8.

40 Liu JH, Zhang X, Kripke DF, et al. Twenty-four-hour intraocular pressure pattern associated with early glaucomatous changes. Invest Ophthalmol Vis Sci 2003;44:1586-90.

41 Liu JH, Kripke DF, Hoffman RE, et al. Nocturnal elevation of intraocular pressare in young adults. Invest Ophthalmol Vis Sci 1998;39:2707-12

42 Herndon LW, Weizer JS, Stinnett SS. Central corneal thickness as a risk factor for advanced glaucoma damage. Arch Ophthalmol 2004;122:17-21.

43 Klyce SD. Stromal lactate accumulation can account for corneal oedema osmotically following epithelial hypoxia in the rabbit. J Physiol 1981;321:49-64.

44 Weinreb RN, Lu A, Beeson C. Maternal corneal thickness during pregnancy. Am J Ophthalmol 1988;105:258-60.

45 Feldman F, Bain J, Matuk AR. Daily assessment of ocular and hormonal variables throughout the menstrual cycle. Arch Ophthalmol 1978;96:1835-8.

46 Soni PS. Effects of oral contraceptive steroids on the thickness of human cornea. Am J Optom Physiol Opt 1980;57:825-34.

47 Nielsen CB, Nielsen PJ. Effect of alpha- and beta-receptor active drugs on corneal thickness. Acta Ophthalmol (Copenh) 1985;63:351-4.

48 Lass JH, Eriksson GL, Osterling L, et al. Latanoprost Corneal Effects Study Group. Comparison of the corneal effects of latanoprost, fixed combination latanoprost-timolol, and timolol: a double-masked, randomized, one-year study Ophthalmology 2001;108:264-71. 